\title{
Two phases in the addition of a poly(A) tail
}

\author{
Michael D. Sheets ${ }^{1}$ and Marvin Wickens ${ }^{1,2}$ \\ ${ }^{1}$ Cell and Molecular Biology Program, ${ }^{2}$ Department of Biochemistry, College of Agriculture and Life Sciences, University of \\ Wisconsin, Madison, Wisconsin 53706 USA
}

The addition of a poly(A) tail has been examined in a HeLa cell nuclear extract using SV40 late RNAs that end at or near the natural poly(A) site. We find that the addition of a full-length, 200-nucleotide poly(A) tail occurs in two discrete phases. In the first phase, the addition of each adenosine is dependent on the highly conserved sequence AAUAAA. Mutations in that sequence result in an accumulation of products that contain 9 or fewer adenosine residues. In the second phase, poly(A) addition no longer requires AAUAAA but, instead, requires the oligo(A) primer synthesized during the first phase. Thus, RNAs carrying an AAUAAA mutation and a $3^{\prime}$-terminal oligo(A) segment are extended efficiently to full-length poly(A). The transition between phases occurs with the addition of the tenth adenosine residue. An activity exists that limits the length of poly(A) added in the extract to $\sim 200$ nucleotides. The two phases share at least one component and are likely to involve the same poly(A) polymerase.

[Key Words: Poly(A); polyadenylation; poly(A) polymerase; mRNA processing]

Received May 17, 1989; revised version accepted July 12, 1989.

The $3^{\prime}$ end of most eukaryotic mRNAs is formed by two sequential reactions (for review, see Darnell 1982; Nevins 1983; Birnstiel et al. 1985; Humphries and Proudfoot 1988; Manley 1988). In the first step, the precursor is cleaved at a specific phosphodiester bond, leaving a 3'-hydroxyl group (Moore et al. 1986; Sheets et al. 1987). In the second, $\sim 200$ adenylate residues [poly $(\mathrm{A})]$ are added to that $3^{\prime}$ end, 1 nucleotide at a time (Moore and Sharp 1985). In this paper we focus on the addition of the poly(A) tail (polyadenylation).

In vivo, polyadenylation is coupled to cleavage and therefore cannot be analyzed in isolation. In vitro, however, the two reactions can be uncoupled (Manley et al. 1985; Zarkower et al. 1986). In particular, polyadenylation can be examined in the absence of cleavage by using synthetic RNA substrates that end at the cleavage site. These precleaved RNAs are polyadenylated efficiently both in cell-free extracts (Zarkower et al. 1986) and in the nucleus of frog oocytes (C. Fox, M. Sheets, and $M$. Wickens, in prep.). The addition of poly(A) to precleaved RNAs requires the sequence AAUAAA (Manley et al. 1985; Zarkower et al. 1986; Skolnik-David et al. 1987). This highly conserved sequence typically is located 15-20 nucleotides upstream of the 3' hydroxyl to which poly $(\mathrm{A})$ is added [the poly $(\mathrm{A})$ site].

In this paper we examine the mechanism of poly(A) addition, using precleaved RNAs. We find that polyadenylation occurs in two distinct phases. In the first phase, the addition of each adenosine requires the AAUAAA sequence. In the second phase, poly(A) addition becomes independent of AAUAAA but, instead, requires the oligo(A) primer synthesized in the first phase.
The activities that add the poly $(\mathrm{A})$ in both phases are as yet indistinguishable and may reside in the same molecule.

\section{Results}

RNA substrates

All RNAs used in this report are derived from the late region of SV40 and are prepared by transcription in vitro, using SP6 polymerase (Melton et al. 1984). Typically, they extend from 58 nucleotides before the poly $(A)$ site to the poly $(\mathrm{A})$ site (i.e., $-58 /+1$ ) or to 6 nucleotides beyond $(-58 /+7)$. These $-58 /+7$ RNAs receive poly $(A)$ without undergoing cleavage and enable us to detect readily intermediates in the polyadenylation reaction (see below). The AAUAAA seqence lies at positions - 13 to -18 .

\section{Requirement for AAUAAA obviated by 3' oligo(A)}

Precleaved RNA is polyadenylated efficiently in nuclear extract. Uniformly labeled RNAs containing either AAUAAA or AAGAAA were incubated with extract for 3,10 , or $30 \mathrm{~min}$. RNA was recovered and analyzed by gel electrophoresis \{Fig. 1). By $30 \mathrm{~min}, 80-90 \%$ of the AAUAAA-containing RNA has received a poly $(\mathrm{A})$ tail of $\sim 200$ nucleotides (lanes $1-4$ ). In contrast, $<10 \%$ of the AAGAAA-containing RNA has received a poly(A) tail (Fig. 1, lanes 13-16). Therefore, as shown previously (Manley et al. 1985; Zarkower et al. 1986), polyadenylation of precleaved RNAs requires AAUAAA. 


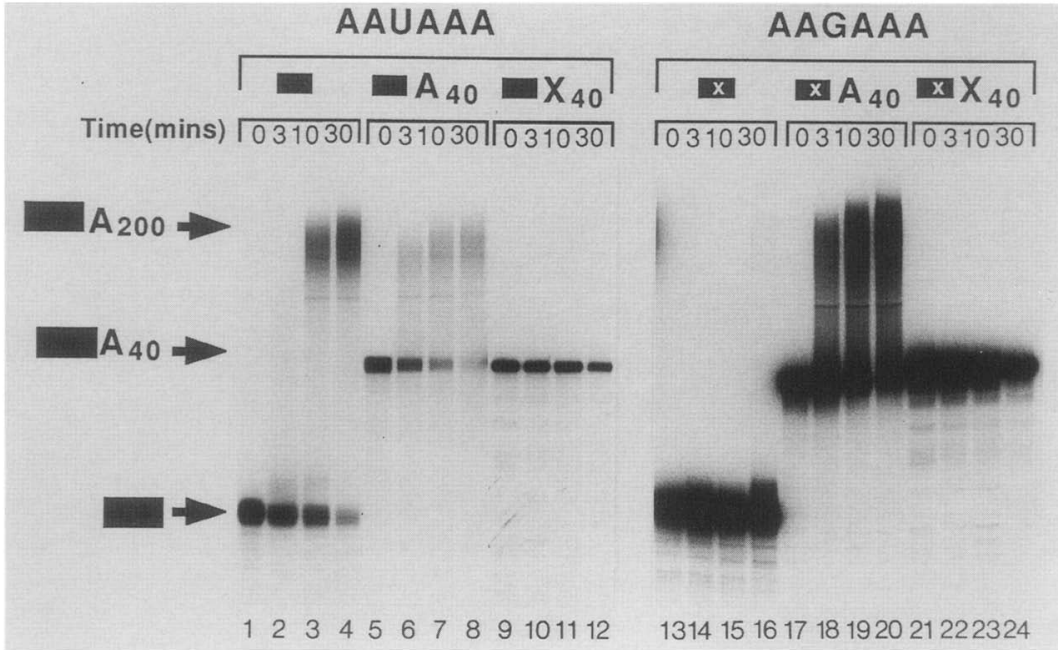

Figure 1. AAUAAA requirement obviated by an oligo(A) tail. Labeled $-58 /+7$ RNA was incubated in nuclear extract under standard conditions for times indicated above each lane. The products were analyzed by electrophoresis through a $10 \%$ polyacrylamide gel. (Lanes $1-4$ ) RNA containing AAUAAA; (lanes 5-8) RNA containing AAUAAA and a 40-nucleotide oligo(A) tail; (lanes 9-12) RNA containing AAUAAA and a tail of 40 nucleotides of vector sequence; (lanes 13-16) RNA containing AAGAAA; (lanes 17-20) RNA containing AAGAAA and a 40-nucleotide oligo(A) tail; (lanes 21-24) RNA containing AAGAAA and a tail of 40 nucleotides of vector sequence.
Is AAUAAA required to add each one of the 200 adenosine residues in the poly(A) tail? To answer this question, we prepared AAUAAA- and AAGAAA-containing RNAs with 40 adenosine residues beyond the poly|A) site. These RNAs were incubated with extract and the products analyzed by gel electrophoresis. The 40-nucleotide oligo(A) tails are extended efficiently to fulllength, 200-nucleotide poly(A) (lanes 5-8). AAUAAAcontaining substrates with and without the oligo(A) primer receive poly $(\mathrm{A})$ with comparable efficiency (Fig. 1 , lanes 1-4 versus lanes $5-8$ ). The reaction that converts $A_{40}$ to $A_{200}$ is largely independent of AAUAAA, as it occurs on substrates containing AAGAAA (Fig. 1, lanes 17-20). Thus, a 3'-terminal oligo(A) segment effectively suppresses an AAUAAA mutation. The suppression is efficient (Fig. 1, lanes 13-16 versus lanes $17-20)$ and restores polyadenylation to the efficiency observed on an AAUAAA-containing RNA without any oligo(A) (lanes 1-4). Suppression of the AAGAAA mutation is specifically due to the tract of oligo(A). RNA with a 40-nucleotide non-poly(A) sequence at its $3^{\prime}$ end is not polyadenylated efficiently (lanes 9-12 and 21-24). Oligo(A) also suppresses an AAUAAA mutation in frog oocytes injected with RNA, demonstrating that the result is not an artifact of the in vitro system (C. Fox, M. Sheets, and M. Wickens, in prep.).

The data in Figure 1 suggest that poly(A) addition may occur in two phases. In the first phase, adenosine addition requires AAUAAA. In the second phase, this requirement is lost; rather, adenosine addition depends on an oligo(A) primer.

\section{Oligoadenylated intermediates}

If each polymerization step in the first phase of polyadenylation were sufficiently slow, then oligoadenylated intermediates might be detected that have too few adenosine residues to trigger the second phase. To identify such intermediates, $-58 /+7$ RNA was incubated with extract for various times. The data are shown in Figure $2 \mathrm{~A}$ and are plotted in Figure $2 \mathrm{~B}$. After $2 \mathrm{~min}, 65 \%$ of the RNAs receiving any adenosine residues have received
$<10$. At later times, the amount of these short products decreases gradually, whereas the amount of full-length poly $(\mathrm{A})$ increases gradually. Thus, by $30 \mathrm{~min},>90 \%$ of the products are full-length poly(A). These kinetics suggest a precursor-product relationship between the short and long species.

The short products contain 9 or fewer nucleotides added in the extract. Products with 10 more nucleotides are conspicuously missing, except for full-length poly(A) (Fig. 2A, lanes 1 and 2). The discrete cutoff after the addition of 9 adenosine residues suggests that the transition from the first to the second phase may occur with the addition of the tenth adenosine residue.

To determine whether the short products are indeed oligoadenylated, we analyzed the sequence of the short product extended by 9 nucleotides (Fig. 3). This product was purified from reactions containing $\alpha^{-32} \mathrm{P} / \mathrm{C}$-labeled $-58 /+7$ RNA as a substrate and then was analyzed by RNase T1 digestion and two-dimensional fingerprinting (Fig. 3D). For comparison, we analyzed $-58 /+7$ RNA that had not been incubated in extract (Fig. 3B) and $-58 /+7$ RNA with 93 '-terminal adenosine residues [added with purified Escherichia coli poly(A) polymerase; Fig. 3Cl.

Each RNA generates seven RNase T1 oligonucleotides, six of which are identical. As expected, the $3^{\prime}$-terminal oligonucleotide of the unreacted substrate (Fig. $3 \mathrm{~B}$, oligonucleotide 1) is missing in the other two RNAs. Rather, RNA to which 9 adenosine residues had been added, using $E$. coli poly(A) polymerase, contains a new 3 '-terminal oligonucleotide [Fig. 3C (oligo) $1+9 \mathrm{~A}$ ]. The same oligonucleotide is generated from the short product purified from extract (Fig. 3D). We conclude that the short product contains a 3 '-terminal oligo(A) segment.

The shortest length of poly $(A)$ that efficiently suppresses a mutation in AAUAAA is 9 nucleotides

The distribution of short products suggests that the second phase of polyadenylation may be triggered by the addition of the tenth adenosine residue. To test this, we 

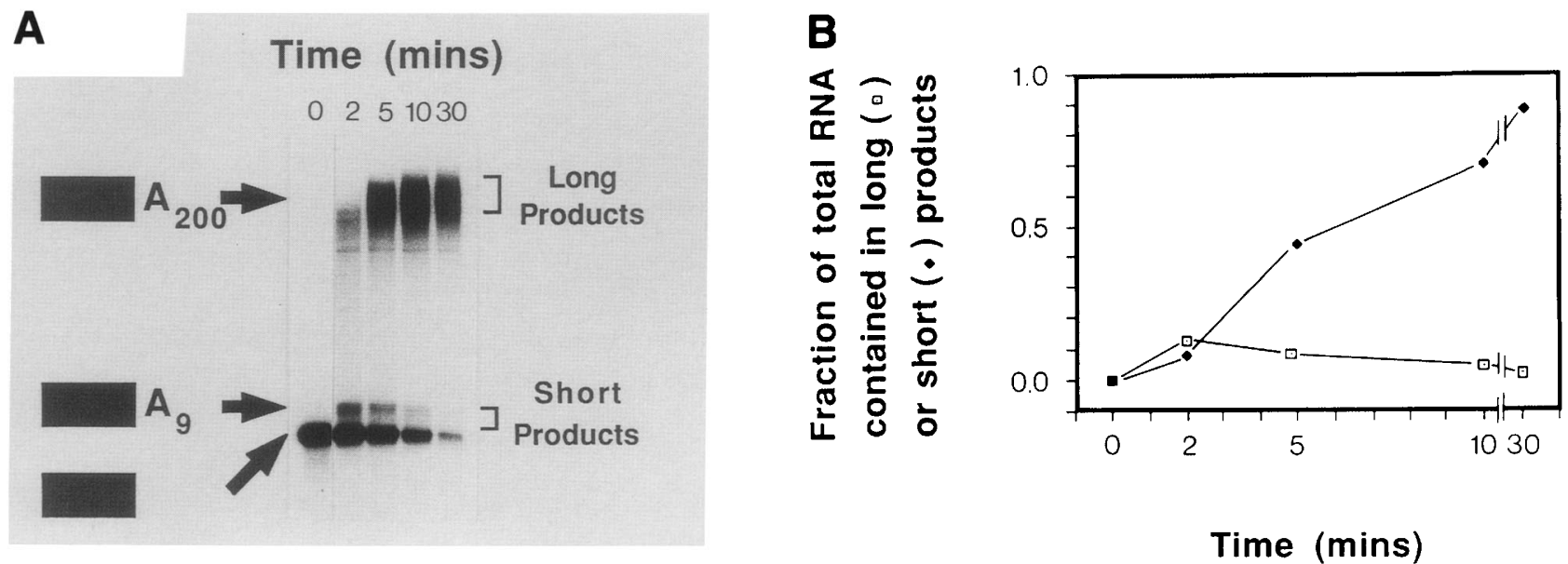

Figure 2. Short intermediates. Labeled $-58 /+7$ RNA was incubated with nuclear extract under standard conditions for various times. The products were analyzed by electrophoresis through a $15 \%$ polyacrylamide gel. $(A)$ Experimental results. AAUAAA-containing RNA incubated with extract for $0,2,5,10$, and $30 \mathrm{~min} .|B|$ Quantitation of the amount of both products versus time. The amounts of short (1-9 nucleotides added), and long ( $>9$ nucleotides added) products were quantitated by scanning densitometry (see Materials and methods). The fraction of total RNA found in each product is plotted versus time of incubation. For example, at 2 min, $13 \%$ of the substrate has received short oligo(A) tails, whereas $8 \%$ has received full-length tails.

A

\section{T1 OLIGONUCLEOTIDES}

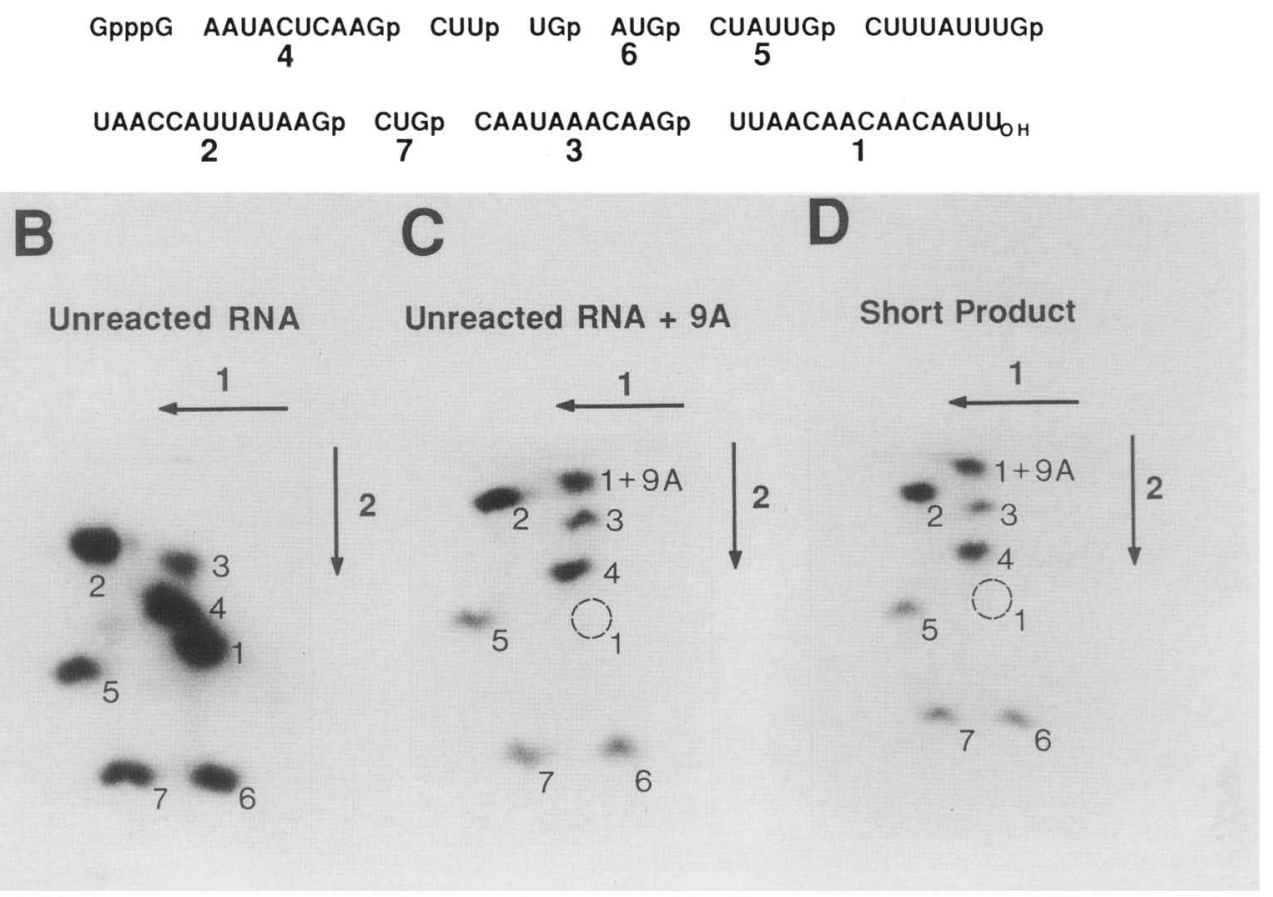

Figure 3. Short products are oligoadenylated. Uniformly $\alpha^{-32} \mathrm{P} / \mathrm{C}$-labeled $-58 /+7$ RNA was incubated in extract for $10 \mathrm{~min}$. The resulting product, 9 nucleotides longer than the $-58 /+7$ RNA, was purified by two rounds of gel electrophoresis. The RNA was digested with RNase $\mathrm{Tl}$, and the products were fractionated in two dimensions by electrophoresis and homochromatography (see Materials and methods). For comparison, $-58 /+7$ RNA and $-58 /+7$ RNA with 9 adenosine residues (9A) added with $E$. coli poly(A) polymerase were analyzed. $(A)$ Sequence and predicted RNase T1 oligonucleotides of $-58 /+7$ RNA. Numbering of the oligonucleotides (numbers given below sequence) are provided. $(B, C$, and $D)$ Experimental results. $|B|-58 /+7$ RNA; $(C)-58 /+7$ RNA with 9 $3^{\prime}$-terminal adenosine residues; $(D)$ the short product extended 9 nucleotides longer than the precursor. (Oligo) $1+9 \mathrm{~A}$ is the new oligonucleotide found in both $C$ and $D$, but not in $B$. The dashed circle in $C$ and $D$ indicates the position at which oligonucleotide 1 would appear if it were present. 
prepared AAGAAA-containing RNAs with 1-16 adenosine residues, using purified $E$. coli poly(A) polymerase. These RNAs then were tested as substrates for the synthesis of a full-length poly(A) tail (Fig. 4).

First we tested a population of RNAs containing oligo(A) lengths ranging from 1 to 16 nucleotides (lane 5). After incubation in extract, only molecules with 9 nucleotides or less remain (lane 6). This distribution is similar to that seen with substrates lacking adenosine residues, but containing AAUAAA (lane 2): RNAs with 10-16 adenosine residues are not detected after incubation (cf. lanes 5 and 6), presumably because they have been extended into full-length poly (A). This conclusion is corroborated by analysis of RNAs having unique oligo(A) tail lengths, ranging from 5 to 15 nucleotides $(7-18)$. The data are quantitated in Figure 4B.

We conclude that at least 10 adenosine residues are required to obviate the requirement for AAUAAA in poly(A) addition. This corresponds well with the discrete cutoff observed after 9 adenosine residues have been added (Fig. 2).

\section{$\operatorname{Poly}(A)$ tails cannot be extended beyond 200} nucleotides

The length of poly(A) added under our standard reaction conditions is 150-200 nucleotides (Fig. 5, lanes 1 and 2). AAGAAA-containing RNAs comprising between 25 and $1203^{\prime}$-terminal adenosine residues are extended to that same final length (Fig. 5, lanes 3-10). However, RNAs with poly $(A)$ tails of 210 or more nucleotides fail to receive any additional poly(A) (lanes 13-16). This failure is a result of the length of the poly(A) tail, not of the overall length of the transcript or the amount of SV40 sequence it contains ( $M$. Sheets, unpubl.). We conclude that a mechanism exists that 'measures' the total length of poly(A) present on an RNA and limits the length of poly $(\mathrm{A})$ added. This limitation is observed with substrates that possess a $3^{\prime}$-terminal oligo(A) tail or that end at the poly $(\mathrm{A})$ site, indicating that the mechanisms by which these two substrates receive poly(A) are similar.

\section{AAUAAA mutations impair each polymerization step in the first phase}

The first phase of polyadenylation requires AAUAAA. To examine this requirement in greater detail, we analyzed three RNAs containing different AAUAAA mutations: AGUAAA, ACUAAA, and AUUAAA (Fig. 6). These mutations vary in the severity to which they impair poly(A) addition. Our biphasic model predicts that at a fixed time, the ratio of full-length poly(A) to short products ( $1-9$ adenosine residues) should vary as a function of the strength of the AAUAAA mutation: 'Strong down' mutants should accumulate more short products than 'weak down' mutants. We analyzed the distribution of products derived from each substrate after a fixed time (30 min; Fig. 6A). The data were quantitated by mi-
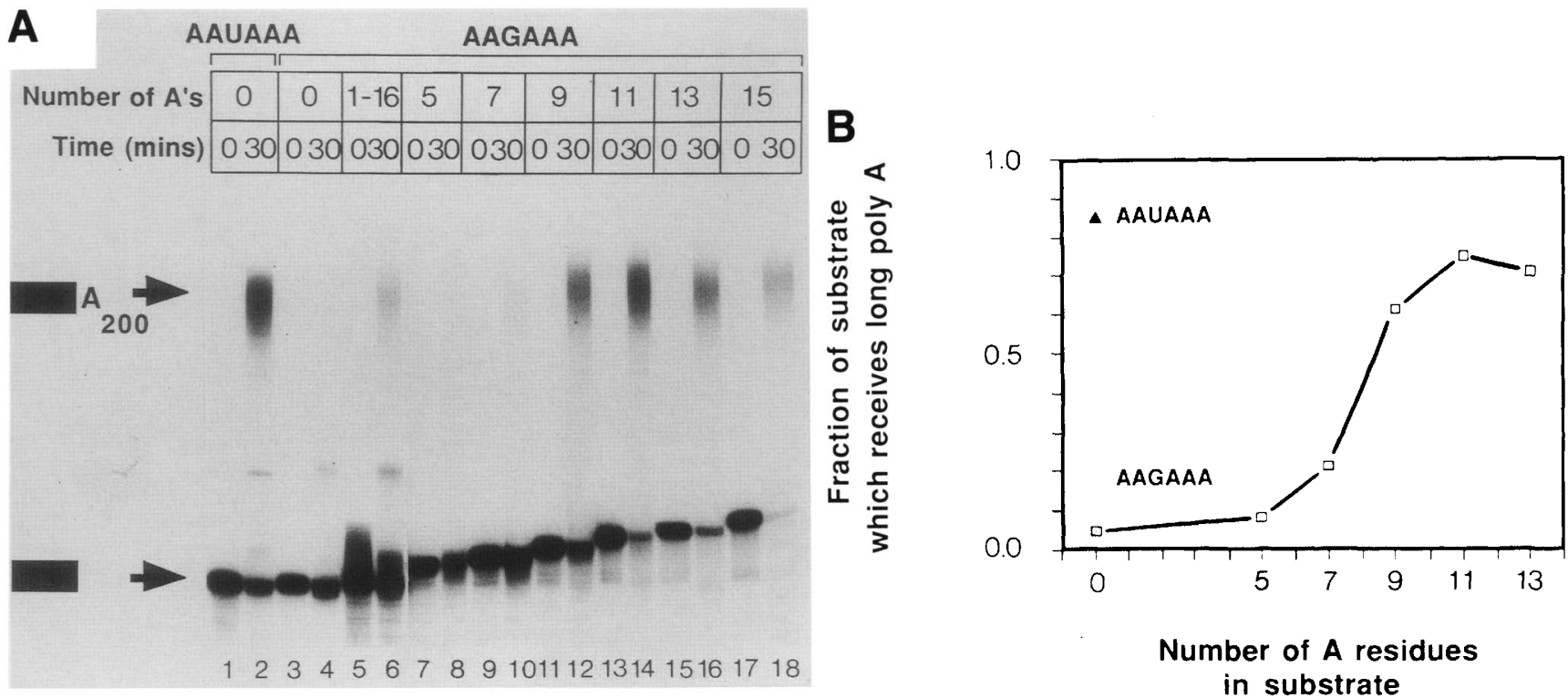

Figure 4. The shortest length of oligo(A) that etticiently suppresses a mutation in AAUAAA is 9 nucleotides. Labeled $-58 /+7$ RNAs were incubated with nuclear extract under standard conditions for $30 \mathrm{~min}$. The products were analyzed by electrophoresis through a $10 \%$ polyacrylamide gel. The RNAs contained either AAUAAA or AAGAAA and a variable number of adenosine residues (A's) added with $E$. coli poly(A) polymerase, as indicated above the lanes. $(A)$ Experimental results. RNA substrates contain AAUAAA and no adenosine residues (lanes 1 and 2); AAGAAA and no adenosine residues (lanes 3 and 4); AAGAAA and $1-16$ adenosine residues (lanes 5 and 6); AAGAAA and 4-5 adenosine residues (lanes 7 and 8); AAGAAA and 6-7 adenosine residues (lanes 9 and 10); AAGAAA and 8-9 adenosine residues (lanes 11 and 12); AAGAAA and 10-11 adenosine residues (lanes 13 and 14); AAGAAA and 12-13 adenosine residues (lanes 15 and 16). (B) Quantitation of polyadenylation efficiency versus number of adenosine (A) residues present in the substrate. The amount of polyadenylated product in each reaction was quantitated by scanning microdensitometry (see Materials and methods). 


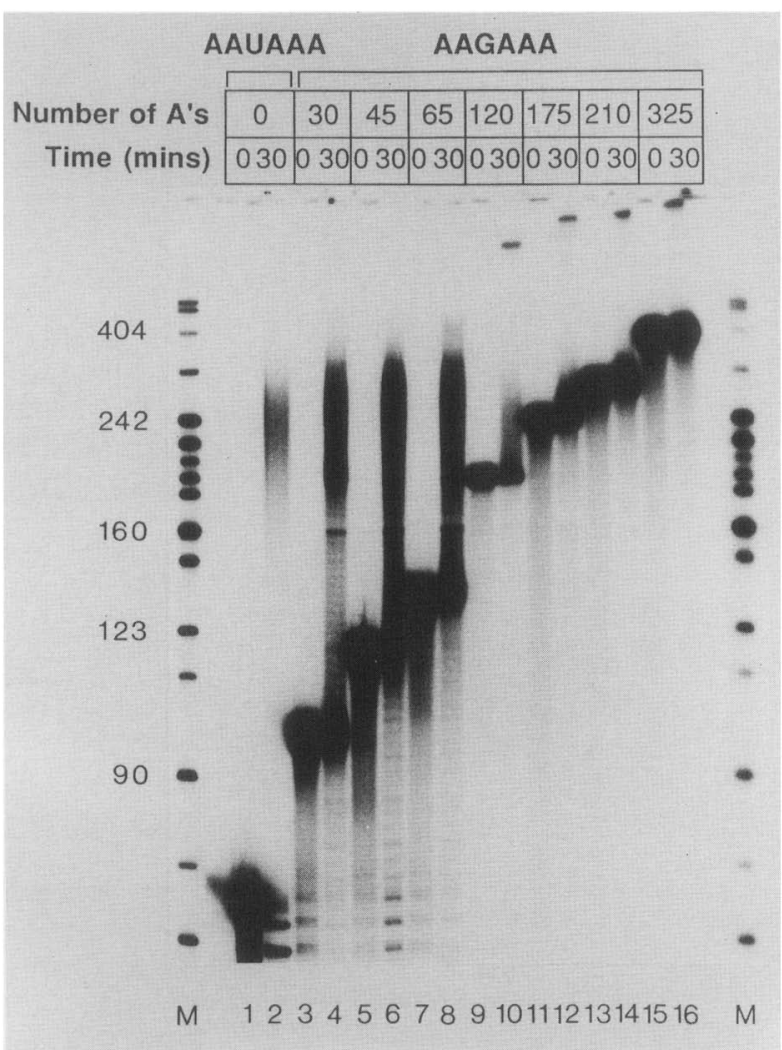

Figure 5. Long polyadenylated products cannot be extended past 200 nucleotides. RNA was incubated with nuclear extract under standard conditions for $30 \mathrm{~min}$. The products were analyzed by electrophoresis through a $10 \%$ polyacrylamide gel. The 'body' of each RNA is $-58 /+7$. The RNAs contain AAUAAA and no adenosine residues (A's) (lanes 1 and 2); AAGAAA and 30 adenosine residues (lanes 3 and 4); AAGAAA and 45 adenosine residues (lanes 5 and 6); AAGAAA and 65 adenosine residues (lanes 7-8); AAGAAA and 120 adenosine residues (9-10); AAGAAA and 175 adenosine residues (lanes 11 and 12); AAGAAA and 210 adenosine residues (lanes 13 and 14); AAGAAA and 325 adenosine residues (lanes 15 and 16). The position and lengths of DNA markers (an MspI digest of pBR322) are indicated $(\mathrm{M})$. The bands of apparent high molecular weight in lanes $10,12,14$, and 16 are artifacts. Their appearance is not reproducible and, in contrast with polyadenylation, does not require $\mathrm{Mg}^{+2}$. They probably are RNA ligation products, as we have observed and characterized RNA circles formed in the extract from shorter but otherwise comparable RNA substrates.

crodensitometry and are presented in Figure 6B. The $\mathrm{x}$ axis indicates the fraction of the substrate that receives poly(A) of any length and therefore reflects the overall severity of the mutation. The $y$-axis indicates the fraction of the total products that contain between 1 and 9 adenosine residues and reflects the efficiency of the transition between the first and second phases.

The fraction of products that contain $<9$ adenosine residues increases with the severity of the mutation (Fig. $6 \mathrm{~A}$ and B). AUUAAA is a mild down mutation: $65 \%$ of the substrate containing this sequence receives at least 1 adenosine residue. Most of the products derived from this substrate have long poly(A) tails. In contrast, only $12 \%$ of the substrate molecules containing AGUAAA receive at least 1 adenosine residue. More importantly, almost half of these products receive $<9$ nucleotides of oligo(A). A third mutation, ACUAAA, lies between AGUAAA and AUUAAA, both in its severity and in the ratio of short to long products that it generates.

We prepared and analyzed 15 other point mutations in AAUAAA to examine this correlation further. Most of these mutations impair polyadenylation so drastically that the data are difficult to quantitate. However, qualitatively, it is clear that these strong down mutations accumulate predominantly short products. The same result is obtained using $-58 /+1$ RNA and adenovinus L3 RNA (data not shown).

As the severity of the mutation increases, the average length of the short oligo(A) segments decreases. The distribution of short products $(<9$ adenosine residues) was quantitated by scanning microdensitometry (data not shown). The oligo(A) segments added to AAUAAA- and AUUAAA-containing RNAs are, on average, between 5 and 9 nucleotides in length: the oligo(A) segments added to AGUAAA and ACUAAA residues are shorter (Fig. 6).

To summarize these results, the length distribution of products generated varies as a function of the severity of the mutation in AAUAAA. Substrates carrying strong down mutations rarely receive any adenosine residues, and few adenosine residues are added on those molecules that do react. Presumably the RNAs with very short oligo(A) tails accumulate because they are too short to prime the second AAUAAA-independent phase of polyadenylation. We conclude that in the first phase of polyadenylation, the addition of each adenosine requires AAUAAA.

\section{The two phases share components}

To determine whether both phases might involve the same factor $(\mathrm{s})$, we tested whether excess substrate for one phase would prevent the other. In the first experiment, we determined whether excess oligo(A) prevents the addition of poly $(\mathrm{A})$ to a substrate lacking any adenosine residues. Labeled $-58 /+7$ RNA containing AAUAAA was incubated with extract in the presence of either oligo $\left(A_{12}\right)$ or oligo $\left(C_{12}\right)$. The oligo $\left(A_{12}\right)$ and oligo $\left(C_{12}\right)$ were not labeled (Fig. $\left.7 \mathrm{~A}\right)$. Polyadenylation of the labeled RNA is inhibited by $5 \mu \mathrm{g}$ of oligo $\left(\mathrm{A}_{12}\right)$ but not by the same amount of oligo( $\left.\mathrm{C}_{12}\right)$ (Fig. 7A).

In the reciprocal experiment, we determined whether excess precleaved RNA without an oligo(A) tail would prevent addition of poly $(\mathrm{A})$ to an oligo(A) primer. We prepared $-58 /+7$ RNAs containing either AAUAAA or AAGAAA as competitors. To ensure that these competitors did not receive any adenosine residues in the extract, a $3^{\prime}$-terminal, $3^{\prime}$-dATP residue was added, using $E$. coli poly $(\mathrm{A})$ polymerase. As a labeled substrate for the second phase, we use AAGAAA-containing RNA with a 30-nucleotide oligo(A) tail. Although both the competitor and the substrate are labeled, both RNAs can be analyzed on a single gel lane because the specific radioactivity of the competitor RNA is only $1 \%$ that of the substrate, and the two RNAs differ in length. 


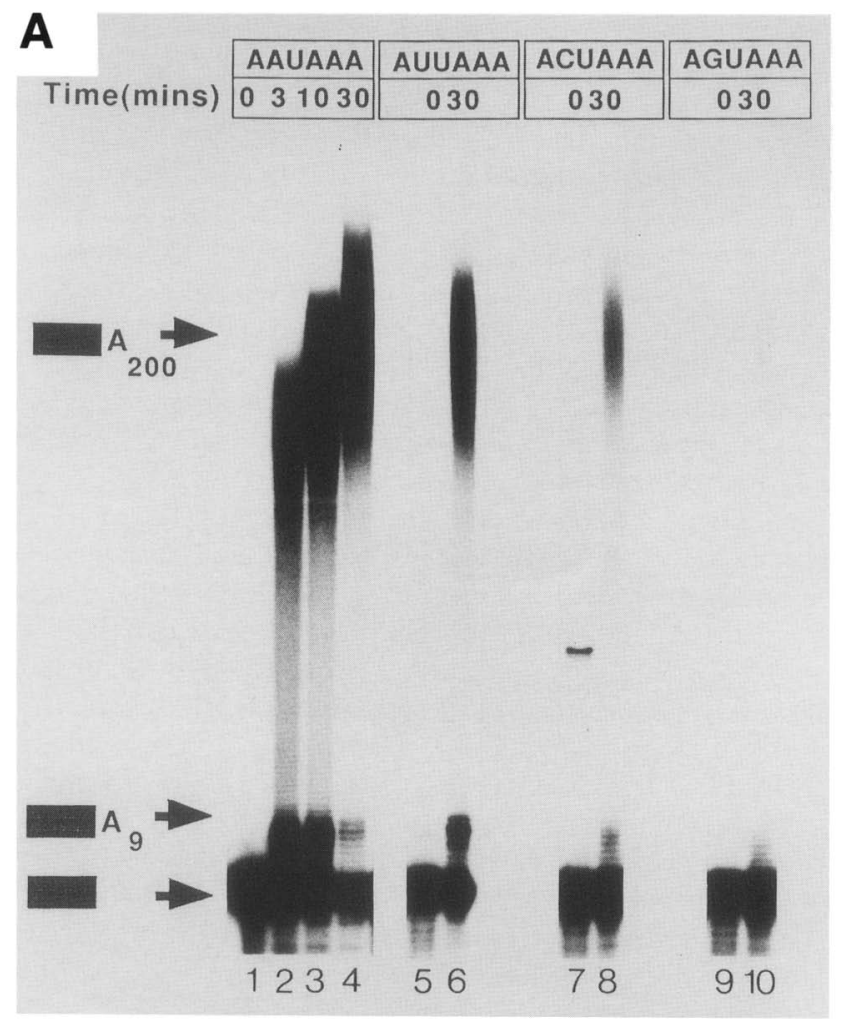

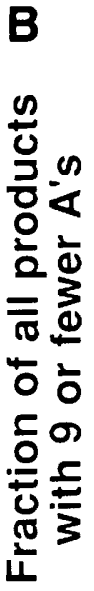

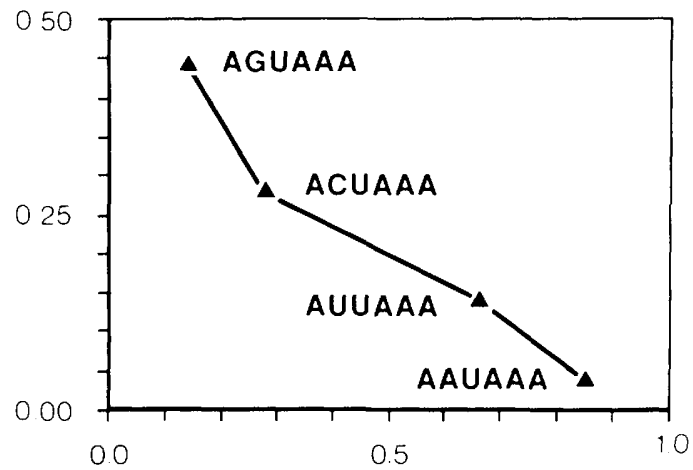

Fraction of RNA with any A's

Figure 6. AAUAAA mutations impair each polymerization step in the first phase. Labeled $-58 /+7$ RNA was incubated with extract under standard conditions for various times. The products were analyzed by electrophoresis through a $6 \%$ polyacrylamide gel. $(A)$ Experimental results. (Lanes 1-4) RNA containing AAUAAA incubated for 0, 3, 10, and 30 min with extract; (lanes 5 and 6) RNA containing AUUAAA incubated for 0 and 30 min with extract; (lanes 7 and 8 ) RNA containing ACUAAA incubated for 0 and 30 min with extract; (lanes 9 and 10) RNA containing AGUAAA incubated for 0 and $30 \mathrm{~min}$ with extract. $(B)$ Quantitation of the relative amounts of short and long products. The amounts of total, short, and long polyadenylated products in each reaction were quantitated by scanning densitometry (see Materials and methods). Short products are defined as those RNAs that have received $1-9$ adenosine residues; long products contain poly $(\mathrm{A})$ tails of $>150$ adenosine residues. On the $\mathrm{x}$-axis is plotted the fraction of the total RNA present that has received any adenosine residues $\langle A$ 's $\rangle$ (i.e., short products + long products/short products + long products + unreacted substrate). On the $y$-axis is plotted the fraction of the total products that are short (i.e., short products/short products + long products).

In the absence of any competitor, the AAGAAA-containing RNA with $303^{\prime}$-terminal adenosine residues is extended efficiently to a full-length poly(A) tail (Fig. 7B, lanes 1 and 2). Addition of a 100-fold excess of AAUAAA-containing competitor RNA greatly reduces the extent of this reaction (Fig. 7B, lane 3). As expected (Zarkower and Wickens 1987a), this competitor also prevents poly(A) addition to an RNA lacking any adenosine residues (lanes 5-7). Thus, this competitor, which lacks an oligo(A) tail, prevents use of a substrate with an oligo(A) tail. The competition is specific: Competitors containing AAGAAA instead of AAUAAA fail to compete (lanes 4 and 8 ).

From these results we conclude that the two phases of polyadenylation must share at least one component. The interaction of this component with an RNA lacking any adenosine residues is dependent on AAUAAA.

\section{The two poly $(A)$ polymerase activities copurify}

To assess whether the same polymerase is involved in the two phases, we determined whether the activity that extends an oligo(A) primer copurifies with the activity that adds a poly (A) tail to a substrate without any adenosine residues. The latter activity was purified partially by a fractionation scheme (Fig. 8A), adapted from a protocol published previously (Christofori and Keller 1988). These fractions, obtained and generously donated by D. Zarkower, then were used in the following experiments.

The activity that adds $\operatorname{poly}(\mathrm{A})$ to a substrate without any adenosine residues can be separated by DEAESepharose chromatography into two fractions. One (DE-100) contains the poly(A) polymerase activity, whereas the other (DE-600) contains a specificity factor thought to be involved in the recognition of AAUAAA (Fig. 8A) (Christofori and Keller 1988, 1989; McDevitt et al. 1988; Takagaki et al. 1988). The polymerase activity present in the DE-100 was purified further by Biorex-70 and Mono-Q chromatography (D. Zarkower, data not shown). Individual fractions of the Mono-Q column were assayed for their ability to catalyze polyadenylation when supplemented with specificity factor (Fig. 8B). A peak of activity centered in fraction 4 is observed. This activity requires AAUAAA (data not shown). The 

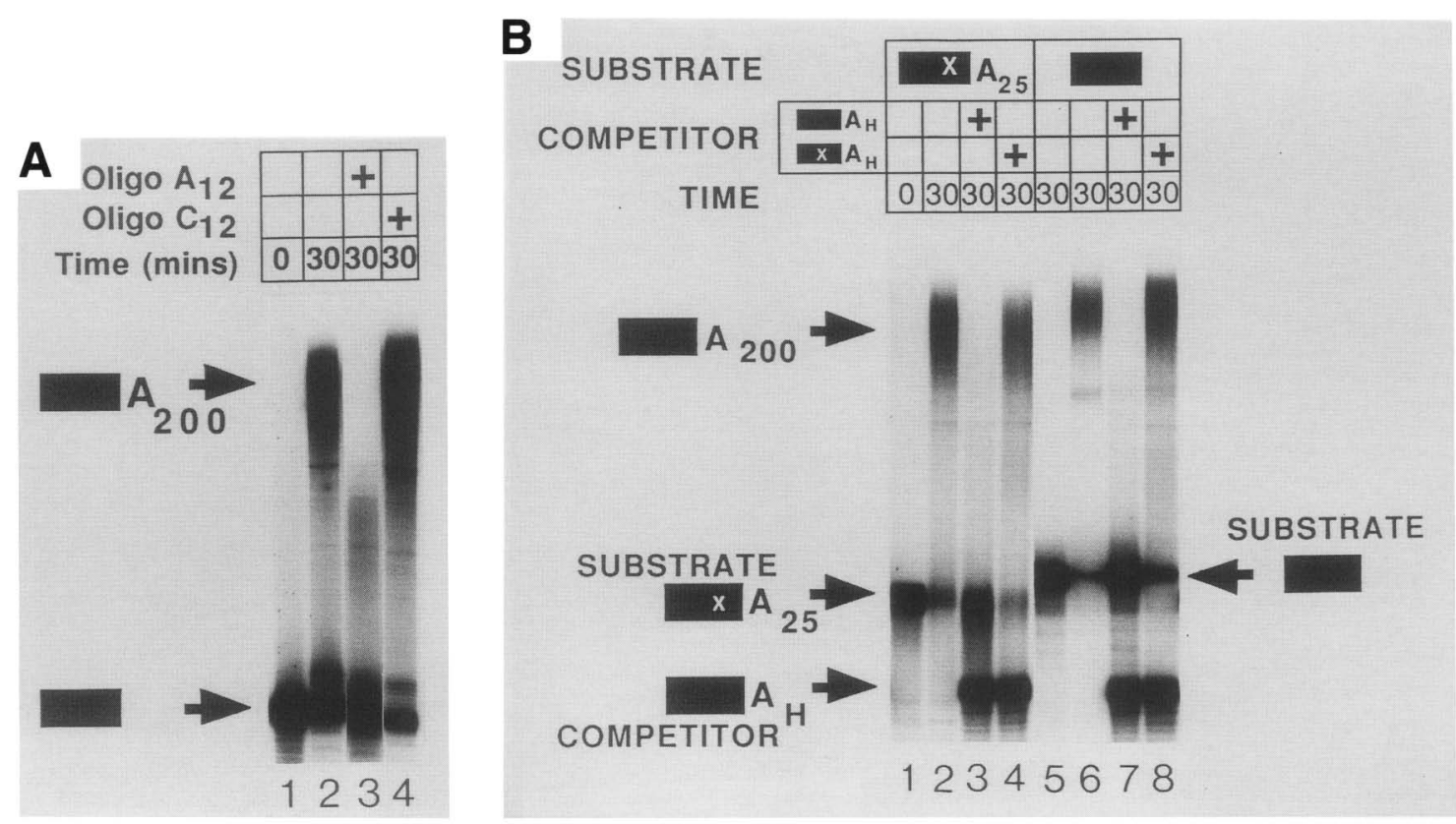

Figure 7. Two phases share common components. Uniformly ${ }^{32}$ P-labeled RNA was incubated in extract with or without competitor RNAs. The products were analyzed by electrophoresis through a $10 \%$ polyacrylamide gel. (A) Polyadenylation of a substrate with no adenosine residues is prevented by excess oligo $\left(\mathrm{C}_{12}\right) .-58 /+7$ RNA was incubated for 30 min in the presence of $5 \mu \mathrm{g}$ of either oligo $\left(A_{12}\right)$ of oligo $\left(C_{12}\right)$, as indicated. $(B)$ Polyadenylation of a substrate with oligo $(A)$ is prevented by an excess of an RNA that has no adenosine residues. Competitor RNAs $\left[-58 /+7\right.$ with a $3^{\prime}$-terminal oligo(A) segment] were synthesized at a sp. act. 100 -fold lower than the substrates being assayed. To prevent these RNAs from receiving poly $(\mathrm{A})$ in the extract, they were modified at their $3^{\prime}$ termini by the addition of a $3^{\prime}$-dA residue using $3^{\prime} \mathrm{dATP}$ and $E$. coli poly $(\mathrm{A})$ polymerase (see Materials and methods). The extent of $3^{\prime}-\mathrm{dA}$ addition was complete, as judged by the failure of these RNAs to receive poly(A) in extract (not shown). The substrates (10-50 fmoles) and competitors (1.75 pmoles) present in each reaction are given above each lane. (Lane 1) RNA containing AAGAAA and a 30-nucleotide poly(A) tail; (lane 2) same RNA as lane 1, incubated in extract; (lane 3) same RNA as in lane 1, incubated in extract in the presence of $-58 /+7$ RNA containing AAUAAA as competitor; (lane 4) same RNA as lane 1, incubated in extract in the presence of -58/ + 7 RNA containing AAGAAA; (lane 5) -59/+1 RNA with no poly(A) tail, incubated in extract; (lane 6) same RNA as lane 5, incubated in extract; (lane 7) same RNA as lane 5, incubated in extract in the presence of - 58/ + 7 RNA containing AAUAAA as competitor; (lane 8 ) same RNA as lane 5 , incubated in extract in the presence of $-58 /+7$ RNA containing AAGAAA as competitor.

activity that extends a short oligo(A) primer, independent of AALAAA, exhibits a very similar activity profile (Fig. 8C), demonstrating that the two activities copurify. However, because the fractions are not yet pure, the possibility remains that the polymerases responsible for the first and second phases are similar but not identical.

To demonstrate that the peak fractions actually are the polymerase, we assayed the same column fractions in the presence of $\mathrm{MnCl}_{2}$, rather than $\mathrm{MgCl}_{2}$ (Takagaki et al. 1988; Christofori and Keller 1989), but without specificity factor(s). Under these conditions, the polymerase exhibits a nonspecific activity that adds poly $(\mathrm{A})$ to any substrate, regardless of AAUAAA. AAGAAAcontaining RNA was incubated with each Mono-Q fraction in the presence of $\mathrm{MnCl}_{2}$ (Fig. $8 \mathrm{D}$ ). A peak of nonspecific activity is centered in fraction 4 . We infer that the activity detected in fraction 4 is likely to be the polymerase.

\section{Partially purified poly $(A)$ polymerase extends a short} oligo(A) primer

To test whether the partially purified poly(A) polymerase could extend an oligo(A) tail in the absence of specificity factor $(\mathbf{s})$, we assayed each Mono-Q fraction alone, using a substrate containing a 30-nucleotide oligo(A) tail and $\mathrm{MgCl}_{2}$. The oligo(A) elongation activity is centered around fraction 4 (Fig. 8E). In parallel experiments (data not shown), these same fractions were found to have no activity using $-58 /+7$ RNA as a substrate, although purer polymerase does. The Mono-Q polymerase fractions extend the oligo(A) tail more efficiently when combined with the specificity factor(s) fraction (cf. Fig. $8 \mathrm{C}$ and $\mathrm{E}$ ).

We conclude that the poly(A) polymerase activities involved in AAUAAA-specific polyadenylation of an RNA without adenosine residues, extension of a short oligo(A) tail, and nonspecific polyadenylation appear to cofractionate. Whether these activities reside in the same molecule will require further analysis and purification.

\section{Discussion}

Addition of a poly(A) tail is biphasic. In the first phase, AAUAAA is required for the addition of each adenosine residue. In the second, addition is independent of 

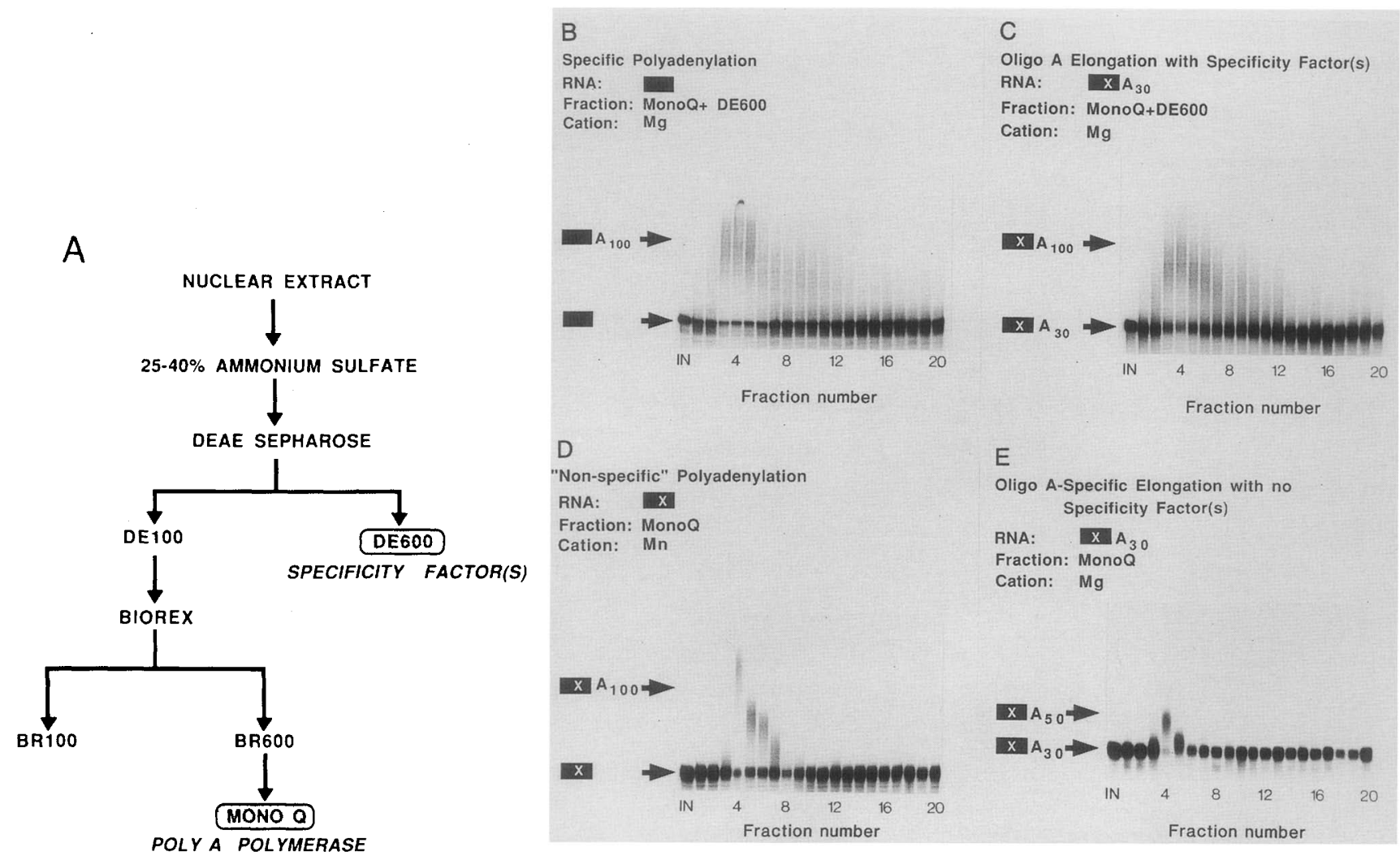

Figure 8. Analysis of polymerase activities. $(A)$ Fractionation scheme used for purification of poly $(\mathrm{A})$ polymerase. The different chromatographic steps are indicated. DE-100 indicates that the material that did not bind to DEAE-Sepharose in $100 \mathrm{mM} \mathrm{KCl}$. Numbers refer to the salt concentrations used to elute particular fractions (for details, see Materials and methods). (B) Specific polyadenylation. Uniformly ${ }^{32} \mathrm{P}-$-labeled $-59 /+1$ RNA was incubated with $4 \mu \mathrm{l}$ of DE-600, and each Mono-Q fraction under standard conditions for $30 \mathrm{~min}$ (the fractions are indicated below the gel lanes). The products were analyzed by electrophoresis through a $10 \%$ polyacrylamide gel. (Lane $I N$ ) (input) is the unreacted precursor RNA; (lanes 1-20) Mono-Q fractions 1-20. (C) Oligo(A) elongation with specificity factor(s). Uniformly ${ }^{32}$ P-labeled $-58 /+7$ RNA containing AAGAAA and a 30-nucleotide poly(A) tail [added with $E$. coli poly(A) polymerase] was incubated with $4 \mu \mathrm{l}$ of DE-600 and each Mono-Q fraction under standard conditions for 30 min. $|D|$ Nonspecific polyadenylation. Uniformly ${ }^{32}$ P-labeled $-58 /+7$ RNA containing AAGAAA was incubated with $4 \mu$ l of each Mono-Q fraction and $0.5 \mathrm{mM} \mathrm{MnCl}$, instead of $\mathrm{MgCl}$, for $30 \mathrm{~min}$. (E) Oligo $(\mathrm{A})$-specific poly $(\mathrm{A})$ polymerase in the absence of specificity factors Uniformly ${ }^{32} \mathrm{P}$-labeled $-58 /+7$ RNA containing AAGAAA and a 30-nucleotide poly(A) tail [added with $E$. coli poly $(\mathrm{A})$ polymerase] was incubated with $4 \mu \mathrm{l}$ of each Mono-Q fraction under standard conditions for $30 \mathrm{~min}$.

AAUAAA; instead, it requires the oligo(A) primer synthesized in the first phase.

Two findings indicate that the short oligo(A) products are bona fide intermediates and not the result of abortive initiation or polymerase pausing. First, the kinetics of product formation are consistent with the short oligoadenylated species, being precursors to full-length poly(A). Second, we detect oligoadenylated RNAs that received $\mathrm{I}-9$ adenosine residues but not 10 or more. The discreteness of this boundary suggests that the transition from the first to the second phase occurs with the addition of the tenth adenosine. Furthermore, the same boundary between 9 and 10 adenosine residues is observed using substrates containing $<9$ adenosines [e.g., a substrate with 5 adenosine residues yields a boundary at 9 rather than 14 (data not shown)]. Thus, the boundary results from a specific effect of 10 adenosine residues, rather than from polymerase pausing or terminating after it has added 9 nucleotides.

The experiments reported here used $-58 /+7 \mathrm{RNA}$ as a substrate. This RNA receives poly(A) without undergoing cleavage (Fig. 3; M. Sheets, data not shown). Comparable results have been obtained using - 58/+1 RNA, which might be regarded as a more physiological substrate for polyadenylation because its $3^{\prime}$ end coincides with the cleavage site (data not shown). In particular, $-58 /+1$ RNA containing mutations in AAUAAA is polyadenylated inefficiently and accumulates short oligoadenylated products. The polyadenylation efficiency of these RNAs can be rescued by the addition of short oligo(A) primers. Unlike $-58 /+7 \mathrm{RNA},-58 /+1$ does not yield a distinct collection of intermediates with a discrete cutoff after 9 adenosine residues. This makes it difficult to pinpoint the transition between phases with this RNA. However, like $-58 /+7$ RNA, 8-12 adenosine residues are required to suppress AAUAAA mutation in $-58 /+7$ RNA. We infer that polyadenylation of both RNAs occurs in two phases with a transition after $\sim 10$ adenosine residues.

The biphasic mechanism may be general. Polyadeny- 
lation of precleaved adenovirus L3 RNA appears to be biphasic: It yields a collection of short, presumably oligoadenylated products (Skolnik-David et al. 1987). Furthermore, L3 RNA containing a mutation to AAGAAA accumulates short oligoadenylated products, and this effect is suppressed by an oligo(A) tail (M. Sheets, data not shown).

Poly(A) synthesis is slow in the first phase but rapid in the second. In the first phase, the addition of each adenosine requires AAUAAA. Polymerization may be processive because, after brief incubations, only a small fraction of the substrate has reacted but has received 9 adenosine residues (Fig. 2). Mutations in AAUAAA may make the reaction distributive by preventing the stable interaction between specificity factors and the substrate, consistent with the failure to detect processing complexes on mutant substrates (Zarkower and Wickens 1987a; Wilusz and Shenk 1988; V.B. Bardwell and $M$. Wickens, in prep.).

Polyadenylation with highly purified vaccinia poly $(\mathrm{A})$ polymerase also occurs in two phases (Shuman and Moss 1988). The vaccinia enzyme generates short intermediates of 10-16 nucleotides, which are converted into long poly $(\mathrm{A})$, much as we observe in the nuclear extract. The vaccinia enzyme consists of two subunits (Moss et al. 1975); by analogy to the extract reaction, perhaps one subunit is the polymerase and the other confers sequence specificity. Regardless, the similar products and kinetics obtained with vaccinia polymerase and nuclear extract may indicate a common two-phase mechanism of poly(A) synthesis.

The existence of two phases may provide an opportunity for regulation. For instance, blocking entry into the second phase would result in RNAs with short adenosine tails. Certain maternal mRNAs possess short poly(A) tails that lengthen at the time of meiotic maturation and/or fertilization /Colot and Rosbash 1982; Rosenthal et al. 1983; Dworkin and Dworkin-Rastl 1985; Huarte et al. 1987; Rosenthal and Ruderman 1987). These increases in poly(A) tail length often are correlated with, and may cause, increases in translational efficiency (for review, see Richter 1987; Rosenthal and Wilt 1987). Clearly, sequences in the body of the mRNA must govern both the block in poly|A| extension and the relief of that block at fertilization. Whether the lengthening of poly $(\mathrm{A})$ tails is biochemically similar to the onset of the second phase is yet to be determined.

In extracts of Saccharomyces cerivisiae, two polymerases with different substrate specificities have been identified: One adds poly(A) to any RNA, whereas the other prefers a short oligo(A) tail (Haff and Keller 1975). This has led to the proposal that two separate poly(A) polymerases are required to add a poly(A) tail. Our data suggest that polyadenylation in the HeLa cell-free system requires only one polymerase. This difference might represent a fundamental distinction between humans and yeast or the impurity of the yeast enzyme. For example, whereas crude human polymerase (DE-100; Fig. 8A) adds poly(A) only to short oligo(A) tails (Fig. $8 \mathrm{E})$, purer enzyme will add poly(A) to any RNA with comparable efficiency (Edmonds 1989; M. Sheets, data not shown).

Components in the specificity factor fraction are required both for recognition of AAUAAA (McDevitt et al. 1988; Takagaki et al. 1988; Christofori and Keller 1989; V.B. Bardwell et al., in prep.) and for efficient extension of the oligo(A) primer (Fig. 8C and $\mathrm{E}_{\text {; }} \mathrm{M}$. Sheets, data not shown). Whether the same molecule interacts with AAUAAA and an oligo(A) primer is not clear, but is suggested by their apparent copurification (Christofori and Keller 1988). If AAUAAA and a short oligo(A) primer were recognized by the same factor, then the two sequences might be interchangeable. It is intriguing that some genes in Dictyostelium contain both AAUAAA and short oligo(A) stretches in regions thought to be important for $3^{\prime}$-end formation (Reymond et al. 1984; Romans and Firtel 1985).

The final length of a poly(A) tail is $\sim 200$ nucleotides, whether the substrate to which poly(A) was added ended at the poly $(\mathrm{A})$ site or in a poly $(\mathrm{A})$ primer. What controls the length of poly $(\mathrm{A})$ added? The length limitation is not exhibited by the purified polymerase alone or by a mixture of the polymerase and specificity factor fraction (D. Zarkower, data not shown), suggesting that another protein controls poly $(\mathrm{A})$ length and has been discarded in the fractionation. By analogy to the bacterial termination factor, rho, a polyadenylation termination factor might function by binding to the poly $(\mathrm{A})$ tail during synthesis. After 200 nucleotides of poly $(\mathrm{A})$ has been added, a structure might form that disengages the poly(A) polymerase from the substrate. Nuclear poly(A)-binding protein is an obvious candidate for such a polyadenylation termination factor; however, we are not aware of any evidence suggesting that this protein forms a unique structure with a 200-nucleotide poly(A) tail.

Complexes between processing factors and polyadenylation substrates have been examined by RNase protection (Hashimoto and Steitz 1986; Humphrey et al. 1987; Stefano and Adams 1988), gel retardation (Humphrey et al. 1987; Skolnik-David et al. 1987; Zarkower and Wickens 1987b; Zhang and Cole 1987), and UV-crosslinking (Moore et al. 1988; Wilusz and Shenk 1988). In each assay, polyadenylation complexes disappear by the time a full-length poly $(\mathrm{A})$ tail has been added. A change in complexes occurs after only $\sim 10$ adenosine residues: At this point, a $68-\mathrm{kD}$ protein no longer can be crosslinked to AAUAAA and the polyadenylation complex becomes heparin-sensitive /V.B. Bardwell and M. Wickens, in prep.). These data, obtained using $-58 /+1$ substrates, support our conclusion that the addition of the poly $(\mathrm{A})$ tail is biphasic.

No single component catalyzes poly(A) addition identical to that seen in the unfractionated extract. The purified HeLa cell polymerase alone adds poly(A) to any RNA, regardless of its sequence, and shows no limitation of poly|A| length. Specificity factor(s), which have no catalytic activity on their own, confer sequence specificity on the polymerase but also are insufficient to regulate length. Components in the specificity factor fraction (i.e., $\mathrm{DE}-600$ ), including the $68-\mathrm{kD}$ protein, bind 
to the substrate in the absence of the polymerase, as long as the substrate contains AAUAAA (P. Wigley and $M$. Wickens, unpubl.). Understanding the interactions between these specificity components, the polymerase, and the RNA substrate and how these interactions change to trigger the transition from the first to the second phase awaits further purification and analysis.

\section{Materials and methods}

\section{Plasmid construction and mutagenesis}

A 128-bp fragment of SV40 spanning the polyadenylation site of virion protein (late) mRNAs [nucleotides 2533-2720 of the SV40 genome; numbering as in Tooze (1981)] was derived from pSPSV $-141 /+70$ (Wickens and Stephenson 1984) and cloned into the HindIII site of pGEM3Z $(\mathrm{f}+)$, generating pSPSV $-58 /$ +70 . This template was cleaved with BsmI, 9 nucleotides past the poly(A) site, and the 2-nucleotide, 3' overhang was removed with T4 DNA polymerase treatment. This DNA was transcribed to produce $-58 /+7$ RNA. This 77 -nucleotide RNA contains 12 nucleotides of vector sequence, followed by $65 \mathrm{nu}$ cleotides of SV40 sequence.

pSPSV $-58 /+7$ was generated by digesting pSPSV $-58 /+70$ with $B s m I$ and SphI, removing the small DNA insert and the single-stranded overhangs with T4 DNA polymerase and resealing the plasmid with T4 DNA ligase. This template was cleaved with EcoRI, 40 nucleotides downstream of the SV40 sequence and transcribed to produce $-58 /+7 / 40 \mathrm{~N}$ RNA. The 123 nucleotide RNA contains 12 nucleotides of vector sequence upstream of the SV40 sequence $(-58 /+7)$ and $45 \mathrm{nu}$ cleotides of vector sequence downstream.

pSPSV-59/+1 contains 60 nucleotides of SV40 sequence cloned into the SmaI site of pSP64. A HaeII linker has been inserted at the cleavage site. This template was cleaved with HaeII and transcribed to produce $-59 /+1$ RNA. This 101-nucleotide RNA contains 41 nucleotides of vector sequence, followed by 60 nucleotides of SV40 sequence, ending at the poly(A) site.

Mutations in the AATAAA sequence of pSPSV $-58 /+70$ and pSPSV $-58 /+7 / 40 \mathrm{~N}$ were generated by the procedure of Kunkel (1985). RNAs generated from these templates are identical to $-58 /+7$ and $-58 /+7 / 40 N$, except for the changes in AAUAAA and a $G \rightarrow C$ change at the -9 position. This latter change does not affect processing (M. Sheets, unpubl.).

\section{RNA synthesis in vitro}

Truncated DNA templates were transcribed in vitro, as described (Melton et al. 1984), except that the reactions contained $0.1 \mathrm{~mm}$ GTP, $1.2 \mathrm{mM}$ GpppG (from P-L Biochemicals) and $50-500 \mu \mathrm{Ci}$ of $\left[\alpha^{-32} \mathrm{P}\right]$ nucleoside triphosphate (Amersham). Full-length RNAs were purified by elution from urea-containing acrylamide gels (Maxam and Gilbert 1980).

\section{Addition of $\operatorname{poly}(A)$ using bacterial poly $(A)$ polymerase}

RNAs were treated with E. coli poly(A) polymerase (Sippel 1973), under conditions recommended by the manufacturer (Pharmacia). The length of poly(A) added was modulated by omitting $\mathrm{MnCl}_{2}$ and varying the concentrations of $\mathrm{MgCl}_{2}$ and ATP in the reaction buffer. When RNAs were modified with 3 dATP, this analog was substituted for ATP and the optimal conditions used.
Preparation of nuclear extract and processing in vitro

Nuclear extract was prepared by the method of Dignam et al. (1983), except that $\mathrm{MgCl}_{2}$ was omitted from buffers $\mathrm{A}$ and $\mathrm{D}$. RNA ( 10 fmole or less) was incubated at $30^{\circ} \mathrm{C}$ in a $12.5-\mu$ l reaction containing $5.5 \mu \mathrm{l}$ of extract (equivalent to $\sim 10^{6}$ cells) and additional components. The final concentrations of the various components (including the contributions of the extract) were as follows: $44 \mathrm{mM} \mathrm{KCl}, 8.8 \mathrm{mM}$ HEPES ( $\mathrm{pH} 7.6$ ), $0.44 \mathrm{~mm}$ EDTA, $2.2 \mathrm{mM}$ DTT, $8.8 \%$ glycerol, $20 \mathrm{mM}$ phosphocreatine, $100 \mu \mathrm{M}$ ATP, and $2.8 \%$ polyvinyl alcohol. The concentration of ATP and $\mathrm{MgCl}_{2}$ were increased to $0.5 \mathrm{~mm}$ when fractions were analyzed instead of extract. To assay nonspecific polyadenylation activity, $0.5 \mathrm{mM} \mathrm{MnCl} 2$ was substituted for $\mathrm{MgCl}_{2}$. After incubation, the RNA was purified as described (Sheets et al. 1987).

\section{Fractionation of extract}

Extract was fractionated essentially as described /Christofori and Keller 1988), except that a $25-40 \%$ ammonium sulfate precipitation was performed prior to chromatography on DEAESepharose.

\section{RNase T1 analysis}

RNAs were mixed with $20 \mu \mathrm{g}$ of tRNA and digested with 10 units of RNase T1 (Calbiochem) for $30 \mathrm{~min}$ at $37^{\circ} \mathrm{C}$, in $10 \mathrm{~mm}$ Tris $(\mathrm{pH} 8.01$, in a 3- $\mu$ l reaction. The resulting oligonucleotides were separated in two dimensions (Barrel 1971; Brownlee 1972), first by high-voltage electrophoresis on cellulose-acetate $\mathrm{pH}$ 3.51 , and then by homochromatography on Cel 300 polyethyleneimine plates (Brinkmann Instruments).

\section{Polyacrylamide gel electrophoresis}

Electrophoresis through 6,10 , or $15 \%$ polyacrylamide gels containing $7 \mathrm{M}$ urea was performed as described /Sanger and Coulson 1978).

\section{Quantitation and scanning desitometry}

For quantitation, films were scanned with a laser microdensitometer; several exposures of the same gel were used. Films were preflashed to ensure linearity of response. Each exposure was checked against standards of known amounts of radioactivity to ensure that the bands in question were in the linear range of the film.

\section{Acknowledgments}

We thank David Zarkower for the fractions used in Figure 8 and all members of the Wickens laboratory for helpful comments and suggestions. We also thank Gerhardt Christofori and Walter Keller for instruction in extract fractionation. We are grateful to Laura Vanderploeg for technical assistance. DNA oligonucleotide synthesis was performed by the Protein Sequence-DNA Synthesis Facility, supported by the U.S. Public Health Service, National Institutes of Health (NIH) (S10rr01684 and CA-07107), a GRS grant to the University of Wisconsin Medical School, and by the University of Wisconsin Graduate School. M.S. is supported by the Cell and Molecular Biology training grant. This work is supported by a research grant (GM-31892) and a Research Career Development Award from NIH (GM-00521) to M.W. 


\section{References}

Barrel, B.G. 1971. Fractionation and sequence analysis of radioactive nucleotides. In Proceeding in nucleic acids research (ed. G.L. Cantonit and D.R. Davies), vol. 2, pp. 751-759. Harper, New York.

Birnstiel, M.L., M. Busslinger, and K. Strub. 1985. Transcription termination and 3' processing: The end is in site Cell 41: 349-359.

Brownlee, G.G. 1972. Determination of sequences in RNA. Elsevier, New York.

Christofori, G. and W. Keller. 1988. 3' Cleavage and polyadenylation of mRNA precursors in vitro requires a poly $(\mathrm{A})$ polymerase, a cleavage factor, and a snRNP. Cell 54: 875-889.

- 1989. Poly(A) polymerase purified from HeLa cell nuclear extract is required for both cleavage and polyadenylation of pre-mRNA in vitro. Mol. Cell. Biol. 9: 193-203.

Colot, H.V. and M. Rosbash. 1982. Behavior of individual maternal poly $(\mathrm{A})^{+}$RNAs during embryogenesis of Xenopus laevis. Dev. Biol. 94: 79-86.

Darnell, J.E. Jr. 1982. Variety in the level of gene control in eukaryotic cells. Nature 297: 365-371.

Dignam, J.D., R.M. Lebovitz, and R.G. Roeder. 1983. Accurate transcription initiation by RNA polymerase II in a soluble extract from isolated mammalian nuclei. Nucleic Acids Res. 11: $1475-1488$.

Dworkin, M.B. and E. Dworkin-Rastl. 1985. Changes in RNA titers and polyadenylation during oogenesis and oocyte muturation in Xenopus laevis. Dev. Biol. 112: 451-457.

Edmonds, M. 1989. Poly(A) polymerases. Meth. Enzymol. (in press).

Haff, L. and E.B. Keller. 1975. The poly(A) polymerases of yeast. I. Biol. Chem. 250: 1838-1846.

Hashimoto, C. and J.A. Steitz. 1986. A small nuclear ribonucleoprotein associates with the AAUAAA polyadenylation signal in vitro. Cell 45: 581-591.

Huarte, J., D. Belin, A. Vassalli, S. Strickland, and J.D. Vassalli. 1987. Meiotic maturation of mouse oocytes triggers the translation and polyadenylation of dormant tissue-type plasminogen activator mRNA. Genes Dev. 10: 1201-1211.

Humphrey, T., G. Christofori, V. Lucijanic, and W. Keller. 1987. Cleavage and polyadenylation of messenger RNA precursors in vitro occurs within large and specific 3' processing complexes. EMBO I. 6: 4159-4168.

Humphries, T. and N.J. Proudfoot. 1988. A beginning to the biochemistry of polyadenylation. Trends Genet. 4: 243-245.

Kunkel, T.A. 1985. Rapid and efficient site-specific mutagenesis without phenotypic selection. Proc. Natl. Acad. Sci. 82: $488-492$.

Manley, J.L. 1988. Polyadenylation of mRNA precursors. Biochem. Biophys. Acta 950: 1-12.

Manley, J.L., H. Yu, and L. Ryner. 1985. RNA sequence containing the hexanucleotide AAUAAA directs efficient mRNA polyadenylation in vitro. Mol. Cell. Biol. 50: 373379.

Maxam, A.M. and W. Gilbert. 1980. Sequencing end-labelled DNA with base-specific chemical cleavages. Methods Enzymol. 65: 507-513.

McDevitt, M.A., G.M. Gilmartin, W.H. Reeves, and J.R. Nevins. 1988. Multiple factors are required for poly(A) addition to a mRNA 3' end. Genes Dev. 2: 588-597.

Melton, D., P.A. Krieg, M.R. Rebagliati, T. Maniatis, K. Zinn, and M.R. Green. 1984. Efficient in vitro synthesis of biologically active RNA and RNA hybridization probes from plasmids containing a bacteriophage SP6 promoter. Nucleic Acids Res. 12: 7035-7056.
Moore, C.L. and P.A. Sharp. 1985. Accurate cleavage and polyadenylation of exogenous RNA substrate. Cell 41: 845-855.

Moore, C.L., J. Chen, and J. Whoriskey. 1988. Two proteins crosslinked to RNA containing the adenovirus L3 poly(A) site require the AAUAAA sequence for binding. EMBO $/$. 7: 3159-3169.

Moore, C.L., H. Skolnik-David, and P.A. Sharp. 1986. Analysis of RNA cleavage at the adenovirus- 2 L3 polyadenylation site. $E M B O$ /. 5: 1929-1938.

Moss, B., E. Rosenblum, and A. Gershowitz. 1975. Characterization of a polyriboadenylate polymerase from vaccinia virions. J. Biol. Chem. 250: 4722-4729.

Nevins, J.R. 1983. The pathway of eukaryotic mRNA formation. Annu. Rev. Biochem. 52: 411-466.

Reymond, C.D., R.H. Gomer, M.C. Mehdy, and R.A. Firtel. 1984. Developmental regulation of a Dictyostelium gene encoding a protein homologous to mammalian ras protein. Cell 39: 141-148.

Richter, J.D. 1987. Molecular mechanisms of translational control during the early development of Xenopus leavis. In Translational regulation of gene expression (ed. J. Ilan), pp. 111-139. Plenum Publishing, New York.

Romans, P. and R.A. Firtel. 1985. Organization of the Dictyostelium discoideum actin multigene family. I. Mol. Biol. 183: $311-329$.

Rosenthal, E.T. and I.V. Ruderman. 1987. Widespread changes in the translation and adenylation of maternal messenger RNAs following fertilization of Spisula oocytes. Dev. Biol. 121: 237-246.

Rosenthal, E. and F. Wilt. 1987. Selective messenger RNA translation in marine invertebrate oocytes, eggs and zygotes. In translational regulation of gene expression (ed. J. Ilan), pp. 111-139. Plenum Publishing, New York.

Rosenthal, E.T., T.R. Tansey, and J.V. Ruderman. 1983. Sequence-specific adenylations and deadenylations accompany changes in the translation of maternal messenger RNA after fertilization of Spisula oocytes. J. Mol. Biol. 166: 309327.

Sanger, F. and A.R. Coulson. 1978. The use of thin acrylamide gels for DNA sequencing. FEBS Lett. 87: 107-1 10.

Sheets, M.D., P. Stephenson, and M. Wickens. 1987. Products of in vitro cleavage and polyadenylation of simian virus 40 pre-mRNAs. Mol. Cell. Biol. 7: 1518-1529.

Shuman, S. and B. Moss. 1988. Vaccinia virus poly(A) polymerase: Specificity for nucleotide and nucleotide analogs. $J$. Biol. Chem. 263: 8405-8412.

Sippel, A. 1973. Purification and characterization of adenosine triphosphate:ribonucleic acid adenyltransferase from Escherichia coli. Eur. I. Biochem 37: 31-40.

Skolnik-David, H., C.L. Moore, and P.A. Sharp. 1987. Electrophoretic separation of polyadenylation-specific complexes. Genes Dev. 1: 672-682.

Stefano, J.E. and D.E. Adams. 1988. Assembly of a polyadenyla tion-specific $25 \mathrm{~S}$ ribonucleoprotein complex in vitro. Mol. Cell. Biol. 8: 2052-2062.

Takagaki, Y., L.C. Ryner, and J.L. Manley. 1988. Separation and characterization of a poly(A) polymerase and a cleavage/ specificity factor required for pre-mRNA polyadenylation. Cell 52: 731-742.

Tooze, J. 1981. DNA tumor viruses (2nd ed.), Cold Spring Harbor Laboratory, Cold Spring Harbor, New York.

Wickens, M.P. and P. Stephenson. 1984. Role of the conserved AAUAAA sequence: Four AAUAAA point mutants prevent mRNA $3^{\prime}$ end formation. Science 226: 1045-1051.

Wilusz, J. and T. Shenk. 1988. A $64 \mathrm{kd}$ nuclear protein binds to 
RNA segments that include the AAUAAA polyadenylation motif. Cell 52: 221-228.

Zarkower, D. and M. Wickens. 1987a. Formation of mRNA 3' termini: Stability and dissociation of a complex involving the AAUAAA sequence. EMBO /. 6: 177-186.

. . 1987b. Specific pre-cleavage and post-cleavage complexes involved in the formation of SV40 late mRNA 3' termini in vitro. EMBO J. 6: 4185-4182.

Zarkower, D., P. Stephenson, M. Sheets, and M. Wickens. 1986. The AAUAAA sequence is required both for cleavage and for polyadenylation of simian virus pre-mRNA in vitro. Mol. Cell. Biol. 6: $2317-2323$.

Zhang, $\mathrm{F}$ and C.N. Cole. 1987. Identification of a complex associated with processing and polyadenylation in vitro of herpes simplex virus type 1 thymidine kinase precursor RNA. Mol. Coll. Biol. 7: 3277-3286. 


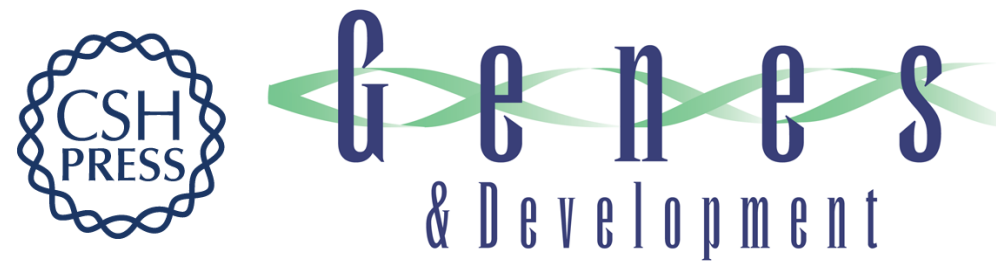

\section{Two phases in the addition of a poly(A) tail.}

M D Sheets and M Wickens

Genes Dev. 1989, 3:

Access the most recent version at doi:10.1101/gad.3.9.1401 $\begin{array}{ll}\text { References } & \begin{array}{l}\text { This article cites } 40 \text { articles, } 11 \text { of which can be accessed free at: } \\ \text { http://genesdev.cshlp.org/content/3/9/1401.full.html\#ref-list-1 }\end{array}\end{array}$

\section{License}

Email Alerting

Receive free email alerts when new articles cite this article - sign up in the box at the top Service right corner of the article or click here.

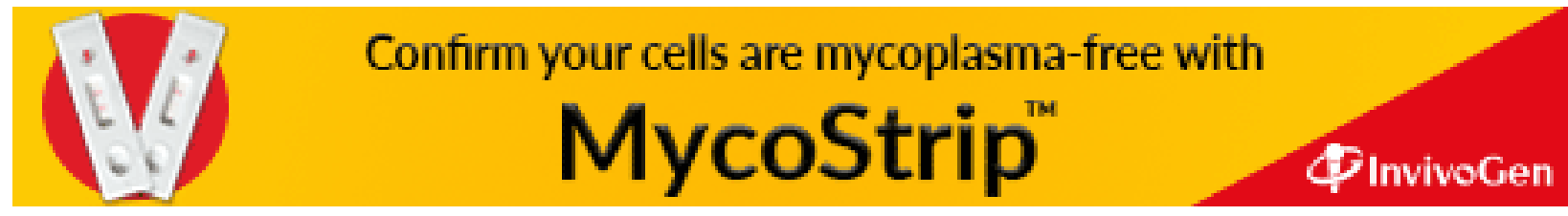

